Araștırma Makalesi - Gönderim Tarihi: 15 . 09 . 2018 Kabul Tarihi: 25.12 . 2018

\title{
Popüler Külttür ve Kültür Endüstrisi Bağlamında ‘Yetenek Sizsiniz Türkiye' Program Formatına Yönelik Eleștirel Bir Analiz
}

\author{
Ali Murat Kırık'
}

Öz

Uzağı yakına getirmeyi sağlayan televizyon; çağımızın en önemli kitle iletişim araçları arasında yer almaktadır. Gerek görsel, gerekse de işitsel boyutu nedeniyle, her yaştan her kesimden izleyiciye hitap edecek içerikleri bünyesinde barındırmaktadır. Televizyon aracılığıyla farklı kültürler, ideolojiler, bakış açıları, yaşam tarzları sunulmakta; bu sayede toplumsal dönüşüm meydana gelmektedir.

Sosyolojik ve psikolojik etkileri de bulunan televizyonun geniş bir program yelpazesi bulunmaktadır. Internet teknolojisinin gelişim göstermesiyle birlikte etkileşimli bir yapıya dönüşen televizyon bu sayede popülaritesini arttırarak devam ettirmiş, farklı program formatları ortaya çıkmıştır. Özellikle Türkiye'de ithal formatlı televizyon programları sayısını her geçen gün artmaktadır. Nitekim bu programlar aynı zamanda popüler kültüre hizmet etmekte ve toplumsal yozlaşmaya adeta zemin hazırlamaktadır. Bu programlardan en dikkat çekici olan "Yetenek Sizsiniz Türkiye" adlı yarışmadır. 2009 yılından itibaren Türkiye'de izlenme rekorları kıran bu yarışma programının orijinali ise "Got Talent" ismiyle birçok ülkede yayınlanmaktadır. Her yaştan her kesimden izleyicinin beğenisini ve dikkatini çeken Yetenek Sizsiniz Türkiye isimli yarışmada kültürün metalaştığı ve kapitalist unsurların sunulduğu görülmektedir. Hedonizm ve empati kavramlarının had safhaya ulaştığı programda jüri üyeleri de kendine özgü tarzları nedeniyle izleyicilerin dikkatini çekmektedir. Bu çalışmada Yetenek Sizsiniz Türkiye isimli yarışma programı popüler kültür ve kültür endüstrisi kavramları eşliğinde derinlemesine irdelenecek, yarışmanın toplumsal değerler açısından taşıdığı önem eleştirel bir perspektifle ele alınacaktır.

Anahtar Kelimeler: Popüler Kültür, Kültür Endüstrisi, Yetenek Sizsiniz Türkiye, Bilgi-Eğlence

Atıf: Kınık, A., M. (2018). “Popüler Kültür ve Kültür Endüstrisi Bağlamında 'Yetenek Sizsiniz Türkiye’ Program Formatına Yönelik Eleștirel Bir Analiz". Akdeniz Üniversitesi İletișim Fakültesi Dergisi,

(AKIL) Aralık (30), s. 31-50 


\section{A Critical Analysis for The Program Format 'Yetenek Sizsiniz Türkiye' (Turkey's Got Talent) In The Context of Popular Culture and Culture Industry}

Television, bringing distance to near, is among the most important mass media of our time. Thanks to its both visual and auditory dimensions, it contains a content that will appeal to audiences from all ages and walks of life. Through television; different cultures, ideologies, perspectives, lifestyles are presented; so, the social transformation happens. The television, which has also sociological and psychological influences, has a wide range of programs.

With the development of Internet technology, television has turned into an interactive structure and continued to increase its popularity by this means and different program formats have emerged. In particular, the number of imported-format television programs in Turkey continues to increase every day. As a matter of fact, these programs serve the popular culture at the same time and pave the way for social corruption. The most remarkable of these programs is the contest named "Yetenek Sizsiniz Türkiye (Turkey's Got Talent)." The original of this competition program, which has been breaking rating records since 2009 in Turkey, has been published in many countries with the name "Got Talent". In the competition named "Yetenek Sizsiniz Türkiye", attracting the admiration and interest of audiences of all ages and walks of life, it is seen that the culture is commodified and capitalist elements are presented. Juries have also been drawing attention in the program, in which the concepts of hedonism and empathy are at the highest level. In this study, the competition program named Yetenek Sizsiniz Türkiye will be examined in depth in the presence of concepts of popular culture and the culture industry. Also, the importance of competition in terms of social values will be filtered from a critical perspective.

Keywords: Popular Culture, Culture Industry, Yetenek Sizsiniz Türkiye (Turkey’s Got Talent), Infotainment 


\section{Giriș}

$\mathrm{G}$ elişen iletişim teknolojileri toplumsal yapıyı derinden etkilemekte ve farklı iletişim araçlarının ön plana çıkmasına neden olmaktadır. Bilgi, haber alma ve eğlenme arzusu iletişim araçlarında yapısal dönüşümler meydana getirmektedir. Bu gelişmelere rağmen yapılan araştırmalar televizyonun hali hazırda etkin bir kitle iletişim aracı olduğu gerçeğini ortaya koymaktadır (RTÜK, 2018: 36) RTÜK tarafından 2018 yılında yayımlanan "Televizyon İzleme Eğilimleri Araştırması"ndan da anlaşılacağı üzere televizyon teknolojisi hali hazırda insan hayatının merkezinde yer almakta, bu durum toplumsal yapıyı da etkilemektedir. Televizyon gelişim göstermiş olduğu ilk günden itibaren evlerin başköşesine yerleşmiş, adeta bir kültür aktarıcısı durumuna gelmiştir. Görsel ve işitsel bir kitle iletişim aracı olan televizyon gelişen teknolojilerden de olumlu bir şekilde yararlanmıştır. Özellikle internet teknolojisinin varlığı televizyona son derece büyük katkı sağlamış, televizyon yayıncıı̆ğı etkileşimli, eş zamansız ve kişiye özgü bir boyuta ulaşmıştır.

Geçmişten günümüze değin uzanan süreçte birçok kitle iletişim aracı gelişim göstermesine rağmen televizyon önemli bir etkileme gücüne sahip olmuş, her yaştan her kesimden bireyi bünyesinde toplamayı başarmıştır. Sunduğu görsel seçenekler nedeniyle diğer kitle iletişim aracına oranla ön planda yer alan televizyon, eğlendirme ve rahatlatma işlevini de üstlenmektedir. Gündelik yaşamın sıkıntısından, stresinden kaçmak isteyen bireyler için televizyon adeta panzehir şeklinde değerlendirilebilmektedir. Kültürel boyutları diğerlerine oranla daha baskın olan televizyon mecrasının birçok kitle iletişim aracına oranla düşük maliyeti izleyici sayısının artmasını sağlamıştır. Televizyon, toplum içerisinde yer alan bireyleri ortak paydada buluşturabilecek nitelikte bir kitle iletişim aracıdır.

Televizyon izleyicilerine adeta büyülü bir dünya sunmakta ve bireyleri bu büyülü dünyanın bir parçası haline getirmektedir. Haber verme, eğitme ve eğlendirme gibi temel işlevleri bulunan televizyonun insanlara sunmuş olduğu içerikler her geçen gün farklılık arz etmektedir. Bununla birlikte, eğlence unsuru ise tabiri caize televizyon yayıncılığının mihenk taşı durumuna gelmiştir. Günümüzde tiraj ve reyting unsurunun ön planda yer alması "infotainment" kavramının ortaya çıkmasına neden olmuştur. Yani haber ve eğlence karışımı programların yaygınlaşması televizyon yayıncılığının farklı bir çehreye bürünmesini sağlamış, böylece program formatlarının sayısı artarak adeta bir endüstri oluşmaya başlamıştır.

Televizyon üzerine birçok araştırma yapılmış ve bu önemli kitle iletişim aracının ekonomik boyutları irdelenmiştir. Tam bu noktada yayıncılık modellerinin önemini vurgulamak gerekmektedir. Yayıncılık modelleri ana hatlarıla ikiye ayrılmaktadır. Bunlardan ilki kamu hizmeti yayıncılık modeli, diğeri ise tecimsel (ticari) yayıncılık modelidir. Kamu hizmeti yayıncılığı modeli İngiliz yayın kuruluşu BBC'ye (British Brodcasting Corparation) dayanmaktadır. Bu modelde yayıncılık devlet mülkiyetindedir. Tecimsel yayıncılık modeli ise finansmanını reklam gelirlerinden sağlamaktadır. 
Televizyon köklü bir geçmişi olan etkin bir mecradır. Televizyonun günümüzdeki halini almasında şüphesiz ki John Logie Baird ismi büyük önem taşımaktadır. Baird, 1926 yılında Londra'da bulunan laboratuvarında ilk televizyon yayını denemesini gerçekleştirmiştir. Dünya tarihinin bugüne kadarki ilk televizyon ekranı $8 \mathrm{~cm}$ eninde ve $5 \mathrm{~cm}$ boyunda olmuştur (Uyguç ve Genç, 1998: 44-45). Televizyon kendinden sonra gelen birçok buluşu da etkilemiş ve iletişimde bir çığır açmıştır.

Televizyon gerek Türkiye'de, gerekse de dünyada oldukça yaygın bir şekilde kullanılmaktadır. Televizyonun etkilerine yönelik araştırmalar hali hazırda gerçekleştirilmeye devam etmekte, bireylerin televizyona dair bakış açıları tespit edilmeye çalışılmaktadır. Paul Lazarsfeld etki araştırmalarını başlatan ve egemen paradigma olması yolunda geliştirdiği tekniklerle bu alanda önemli bir rol üstlenmiştir (Erdoğan, İşler ve Durmuş 2005: 1-2). Kanadalı iletişim bilimci Marshall McLuhan'a göre de medyanın bir etki boyutu vardır. Bilindiği üzere McLuhan; "araç mesajdır" olgusunu ortaya koymuş ve iletinin aracın bizzat kendisi olduğunu dile getirmiştir. Yani anlatılanın bir önemi yoktur. Mühim olan aktarandır (Esslin, 1996: 11). Nitekim televizyon dünyada var olan her türlü gelişmeyi izleyicilere aktarabilmiş, bir bilgi kaynağı halini almıştır. Fakat bu bilginin doğruluğuna yönelik şüpheler hali hazırda devam etmektedir.

Televizyonun temel işlevleri bulunmaktadır. Haber verme, bilgilendirme, eğitme ve eğlendirme bu işlevler arasında yer almaktadır. Birçok araştırmada televizyonun bir eğlence aracı olduğu ifade edilmektedir. İzleyiciler televizyon aracılığıyla zevkli ve neşeli vakitler geçirmektedir. İnsan doğası gereği eğlenmeyi sevmektedir. Mevcut koşullar gereği eğlence üzerine araştırmalarını yapan Bosshart ve Macconi (1998: 5) zevk kavramını dört başlık altında toplamışlardır:

Toplumsal heyecanların zevki: Başkalarına empati kurma, özdeşleşme zevki. Başkaları için heyecan hissetme.

- Benlikle ilgili heyecanlarla duyulan zevk: Duyguların yavaş yavaş uyanması, duygusal durum değişiklikleri...

- Duyusal zevk: Fiziksel yeteneklerin kullanımı esnasında duyu sistemi aracılığıyla meydana gelen zevk.

- $\quad$ Bilgi zevki ve kişisel zekâ: Zihinsel güçlerin kullanımında bireyin kendi zekasını kullanırken hissettiği yeterlilik duygusu

Televizyonun daha çok bir eğlence aracı olarak kullanılması yapılan araştırmalarda da ortaya çıkmıştır. Televizyonu yalnızca olumsuz bir kitle iletişim aracı olarak nitelendirmek çok doğru olmayacaktır. Çünkü televizyonun hayatı geliştirici etkisinin olduğunu söyleyebilmek mümkündür. Televizyon aracılığıyla dünyadaki gelişmeler eş zamanlı bir şekilde takip edilebilmektedir. Televizyon izlendiği esnada eğlenme ve öğrenme birlikte gerçekleşebilmektedir. Televizyon kuşaklar arası farkların hissedilmediği bir kitle iletişim aracıdır. Daha geniş kesimlere ulaşabilmektedir. Uydu ve internet yayınları aracılığıyla fiziki sınırlar ortadan kalkmış, farklı kültürlerin öğrenebilmesi sağlanmıştır. Televizyon programları aracılığıyla izleyicilerin bilinçlendiği de bir gerçektir. Bireylerin 
bakış açılarını genişleten televizyon aynı zamanda bir aile etkinliği olarak ifade edilebilmektedir. Taşınabilir iletişim araçlarına karşın aile bireylerini bir arada tutabilen nadir araçlardan bir tanesidir. Televizyonu sadece eğlence ile sınırlandırmak doğru değildir. Aynı zamanda eğitsel bir mecradır (Aksaçlığlu ve Yılmaz, 2007: 8) Televizyon her yaştan her kesimden bireyin ilgisini çekmekte ve bireylerin hayata yönelik fikirlerini tekrardan biçimlendirebilmektedir.

Küreselleşmenin etkisiyle birlikte televizyon programlarının da boyutları değişmiş, birbirinden farklı yapıya sahip program formatları tüm dünya genelinde hızla yayılmaya başlamıştır. Küreselleşme neticesinde kültürler, ürünler, hizmetler, ekonomiler birbirine daha yakın ve bağımlı bir hale gelmekte; dünya ekonomisi ise tek pazara dönüşmektedir. Televizyon yayıncılığının tam da bu noktada önemi daha açık bir şekilde ortaya çıkmaktadır. Çünkü yabancı formatlı programların giderek yaygınlaşması ve ülkelerin yayın stratejilerini bu programlara göre kanalize etmesi bu alanda bir dönüşüm sürecinin yaşanmasını sağlamıştır. Aynı zamanda yabancı formatlı programların kültürel etkileri de bulunmaktadır.

Çağımızda popüler kültür, çabuk tüketilen ve hızı kullanılan ürünleri bünyesinde barındırmaktadır. Yabancı formatlı televizyon programları da bu kültürün bir parçası durumuna gelmiştir. Programlar aracılığıyla sunulan hayatlar, yaşam tarzları ve rekabet ortamı ise kültür endüstrisinin bir parçası halini almıştır. Geçmişten günümüze değin geçen süre zarfında kültür; alınıp satılan bir meta haline gelmiş, kendi endüstrisini oluşturmuştur. Bu çalışmada; Türkiye'de yoğun ilgiyle izlenen yabancı formatlı "Yetenek Sizsiniz Türkiye” programı popüler kültür ve kültür endüstrisi bileşkesinde çözümlenmiş ve programın yapısı, içeriği ve kapsamı eleştirel bir perspektifle ele alınmıştır.

\section{Popüler Kültür Olgusuna Genel Bakıș}

Popüler kültür özellikle 20.yüzyılda etkisini derinden hissettiren ve toplumsal modernleşmede önem arz eden bir kavram olarak karşımıza çıkmaktadır. Popüler kültür gerek Türkiye'de, gerekse de dünyada yoğun tartışmalara sahne olmuştur ve hali hazırda olmaya devam etmektedir. Mukerji ve Schudson (akt. Mutlu, 2005: 313); popüler kültürün "bir toplumda geniş bir şekilde paylaşılan inançları, pratikleri ve bunların örgütlendiği nesneleri dile getirdiği"ni belirtmektedir. Nitekim popüler kültür toplumsal bir olgudur ve içinde yaşadığı toplumu etkileyecek güce sahiptir. Bu nedenle bu kavrama yönelik farklı tanımların yapıldığı görülmektedir. Hall'a (akt. Özbek, 2002: 90) göre popüler kültür kavramı; kitle iletişim araçlarının yaydığı kültürün dışında yaşayan bir kültürün olduğu varsayımını temele almaktadır. Bu açıdan popüler kültür, kitle kültüründen ayrılmaktadır. Çünkü kitle kültürü atomize olmuş bireylerden oluşmakta olup çeşitlilikten yoksundur.

Popüler kültürü gündelik hayattaki baskın kültür şeklinde de nitelendirebilmek mümkündür. Popüler kültür bağımlı bireylere sunulan bir kültür türüdür. Daha yüzeysel bir ifadeyle; emeğin gündelik olarak yeniden üretilmesinin bir girdisi olarak eğlenceyi merkeze almaktadır. Yani belirli bir yaşam tarzının ideolojik olarak yeniden üretilmesini 
sağlamaktadır (Coşgun, 2012: 840). Mutlu (2005: 313-314) ise daha genel bir bakış açısıyla popüler kültüre yaklaşmış ve kapsamlı bir tanım yapmıştır. Ona göre popüler kültür; "kökleri yerel geleneklerde bulunan halk inançlarını, pratiklerini ve nesnelerini, keza siyasal ve ticari merkezlerde üretilen kitlesel inançları, pratikleri ve nesneleri içerir; popüler kültürün içeriğinde popülerleştirilmiş seçkin kültürel biçimlerin yanı sıra müze geleneği düzeyine yükseltilmiş popüler biçimler de bulunmaktadır." Popüler kültüre yönelik önemli araştırmalar gerçekleştiren bir diğer önemli isim ise Raymond Williams'tır. Williams, kültürün gündelik bir yaşama alanı olduğunu vurgulamıştır. Ona göre kültür, hegemonya oluşturma çatışmalarının gerçekleştiği bir çatışma alanıdır (Türkoğlu, 2003: 55-56).

Popüler kültürün egemen ekonomik ve toplumsal ilişkileri desteklediği görülmektedir. Kitle üretimi yapan pazarın, siyasal, ekonomik ve bilişsel bir yansıması olan kitle kültürünün somut şekillerinden biridir. Popüler kültürün endüstriyel boyutları da bulunmaktadır. Çünkü sermaye ve sermaye sisteminin devam edebilmesi adına birincil derecede önemlidir. Müzik, gıda, gündelik yaşamda hep bir tüketici, müşteri kazanma, elde etme durumu söz konusudur. Bireysel özgürlükler, tercihler ve zevkler popüler kültürle birlikte şekillenmektedir. Bununla birlikte popüler kültürün oluşturulmasında popüler unsurların kullanıldığı görülmektedir (Erdoğan, 2004: 4-5). Bu unsurlar arasında popüler sporcular, futbol gibi popüler sporlar, sanatçılar, müzisyenler, popüler ideolojiler ve fikirler, popüler televizyon programları ve karakterleri, popüler politikalar ve popüler unsurlar yer almaktadır.

\section{Popüler Kültürün Toplumsal Hayata Etkileri}

Popüler kültür ile tüketim arasında organik bir bağ bulunmaktadır. Çünkü insanoğlu gerek bireysel, gerekse de toplumsal açıdan tüketim sağlamakta, kimi zaman da üretim sürecine dâhil olmaktadır. Bu üretim ise zaman içerisinde gerçekleşmektedir. Popüler kültür öğelerinin temelinde de insan unsuru yer almaktadır. Popüler kültürde; toplumun her bireyinden, tarihin her köşesinden, gündelik yaşam içerisindeki değerlerden, gelenek ve göreneklerden, hayat deneyimlerinden yoğun izler bulunmaktadır. Popüler kültürde gerek üretimsel, gerekse de tüketimsel açıdan yaklaşıldığında hemen hemen her kesimden bireyin bu olguya ilgi duyduğunu söyleyebilmek mümkündür. Çünkü popüler kültür aynı zamanda bir etkinlik alanıdır. En alt tabakadan en üst tabakaya kadar zengin bir spektruma sahip olan popüler kültürün her eğitim düzeyinden, her yaştan, her cinsiyetten tüketicisi mevcuttur (Güngör, 1993: 9). Bundan dolayı popüler kültür her geçen gün etki alanını arttırmakta ve kapsama alanını genişletmektedir.

Popüler kültür diğer kültür türlerinden ayrılmaktadır. Sürekli değişken, güncel ve kısa vadeli bir yapıya sahiptir. Bununla birlikte popüler kültür ürünleri, endüstrinin yardımıyla birlikte üretilmekte ve tüm topluma dağıtılmaktadır. Popüler kültür ürünleri aynı zamanda meta olarak değerlendirilmektedir. Popüler kültürün ekonomik boyutları da söz konusudur. Popüler kültürün ekonomik açıdan yaşayabilmesi, varlığını sürdürebilmesi için birtakım toplumsal olaylarda etkisini hissettirmesi gerekmektedir. Çünkü popüler kültürün kazandığı kaynaklar toplumsal farklılıklar üzerinde etkisini 
hissettirmektedir. Buradan işaretle popüler kültürün, merkez ve çevre, iktidar ile halk oluşumları, tekil metinler ile farklı okumalar arasında bulunduğu söylenebilmektedir (Fiske, 2010: 2-5). Çünkü popüler kültür bir yönüyle hem ideolojik hem de ekonomik bir yapıya sahiptir. Stratejik çıkarlar ön planda bulunmaktadır. Popüler kültür kimi zaman da çatışmanın kültürüdür. Bu yönüyle halk kültüründen keskin hatlarla ayrılmaktadır.

Popüler kültür ile egemen yapı arasında çift yönlü bir etkileşim söz konusudur. Diğer bir ifadeyle popüler kültür mücadele sahasıdır. Popüler kültür, egemen güçlerin nüfuzunu kabul etmekle birlikte dikkatini popüler taktikler üzerine toplamaktadır. Popüler olabilmek için kültürel ürünler zıt gereksinimleri de karşılamak zorundadır. Daha çok tüketiciye ulaşmak popüler kültürün en temel hedeflerindendir. Daha çok tüketici daha çok gelir anlamına gelmektedir. Popüler kültür bu nedenle daha çok tüketiciye ulaşabilmek adına ürünler ortaya çıkarmakta, böylece gelir seviyesini arttırmayı amaçlamaktadır. Ürünlerde yer alan toplumsal farklılıklar reddedilmektedir. Popüler kültür toplumsal düzenin disiplinsel ve ideolojik gerekleriyle birlikte hareket etmektedir. Popüler güçler kültürel ürünleri kaynak haline dönüştürmekte, ürünlerin sunmuş olduğu anlamları ve zevkleri çoğullaştırmaktadır. Popüler kültür; ürünlerin bütünlüğünü ve homojenik yapısını bozmaktadır. Kısacası popüler kültür toplumsal deneyimin anlamları üzerine bir mücadele olarak nitelendirilebilmektedir (Storey, 2000: 36-37).

\section{Popüler Kültürün Temel Özellikleri}

Popüler kültürün oluşumunda medyanın rolü de oldukça büyüktür. Çünkü medya ve popüler kültür arasında sıkı bir bağ bulunmaktadır. Medya, popüler kültürün oluşumunda temel göreve sahiptir. Aynı zamanda popüler kültür ürünlerinin geniş kitlelere ulaşması yine medya aracılığıyla gerçekleşmektedir. Popüler kültür ürünlerinin merkezinde yer alan merak ve eğlence faktörünü tetikleyen ise medyadadır. Medya günümüzde eğlenceye hizmet edecek bir duruma gelmiştir. Dolayısıyla popüler kültür ve medya arasındaki ilişki oldukça ileri düzeydedir (Curran, 1997: 146). Popüler kültürün bir takım özellikleri bulunmaktadır. Bu özellikler onu, diğer kültür türlerinden ayırt etmektedirler. Bu özellikleri aşağıdaki şekilde sıralayabilmek mümkündür (Çiğdem, 2005: 50):

- $\quad$ Popüler kültür biçimsel olarak orta karmaşıklıktadır.

- $\quad$ Popüler kültür ürünleri genelde maddiyatla elde edilmektedir.

- $\quad$ Popüler kültür ürünleri doğrudan tüketiciye yöneliktir.

- $\quad$ Popüler kültür üreticileri ve sunucuları tamamen profesyoneldir.

- $\quad$ Popüler kültür ürünlerinin bilinen bir kaynağı ve üreticisi bulunmaktadır.

- $\quad$ Popüler kültür ürünlerini üreten ve tüketen arasında toplumsal bir statü farkı bulunmaktadır.

- $\quad$ Popüler kültür, kültürel değerleri, görenekleri, gelenekleri yeniden biçimlendirerek yansıtmaktadır.

- $\quad$ Popüler kültür öğeleri; biçimlendirilmiş, standart hale getirilmiş veya çoklaştırılmış olarak tüketicilere sunulmaktadır.

- $\quad$ Popüler kültür ürünleri sahiplik veya patent yolu aracılığıyla tüketime açıktır.

- $\quad$ Popüler kültür ürünlerinin iletimi veya aktarımı ortam ve teknoloji vasıtasıyla 
dolaylı bir şekilde gerçekleştirilmektedir.

- $\quad$ Popüler kültür bir çatışma kültürü olup, diğer kültür türleriyle de bu çatışmayı sürdürmektedir.

- $\quad$ Sanayi devrimi sonrası kent kültürünün bir ürünü sayılabilmektedir.

- Kendi varoluş koşullarını üretmemekle birlikte mevcutla yetinmeye çalışmaktadır.

\section{Kültür Endüstrisi Ekseninde Televizyon Yayıncılığı}

Kültür endüstrisi günümüzde oldukça önemli ve derin izler taşıyan bir kavramdır. Bu kavramın medyayla olan bağı da dikkate değerdir. Bu kavramı ilk olarak Frankfurt Okulu düşünürlerinden Theodor W. Adorno (2009: 209) ve Max Horkheimer kullanmıştır. Frankfurt Okulu, eleştirel okul olarak bilinmektedir. Dönemin ekonomik ve politik şartlarına bir tepki olarak doğmuştur. Frankfurt Okulu'nun önde gelen isimlerinden Adorno modern yaşamın birey ve kültür üzerinde olan etkisini kültür endüstrisi kavramıyla açıklamaya çalışmaktadır. Bu nedenle kültür endüstrisi kavramını derinlemesine irdelemek yerinde olacaktır

Kültür endüstrisi oldukça dikkate değer bir kavramdır. Çünkü artık kitleler kültür endüstrisinin öznesi durumunda değildirler. Kitleler kültürün müşterisi yani nesnesi durumuna gelmişlerdir. Kültür endüstrisi müşterilerini yani tüketicilerini eğlence aracılığıyla etkileme potansiyeline sahiptir. Eğlence olgusu geç kapitalizm nedeniyle çalışma fiilinin bir uzantısı, emek gücünü sarf eden bireylerin mekanik süreçten kaçmak nedeniyle başvurduğu bir yoldur. Eğlence çoğu zaman bireylerin hiçbir şeyi düşünmemelerine neden olmakta, sunulduğu esnada acıyı unutmayı sağlamaktadır. Eğlence aracılığıyla kitleler kendilerini unutmakta, teslimiyetlerini arttırmaktadırlar. Böylelikle var olan mevcut sistemle hemfikir olmaktadırlar (Adorno, 2009: 110) Anlaşılacağı üzere kültür endüstrisi kavramı, kitleleri kendine göre uyarlamakta ve onların rızasını kazanmayı amaçlamaktadır.

Adorno ve Horkheimer kültür endüstrisinin tüketimle doğru orantılı olduğunu ifade etmişlerdir. Çünkü tüketim olgusu reklamcılığın etkisiyle birlikte had safhaya ulaşmaktadır. Reklamlar, zaman zaman anlamsız gibi gözükse de kitleler tarafından ilgi görmektedir. Kültür endüstrisi kapsamında üretilen ürünler daha planlı ve çoğulcu bir üretime dayanmakta, programlar, içerikler yalnızca stüdyolarda üretilmemekte, aynı zamanda belgesellerden, romanlardan ve hatta hit şarkılardan da oluşmaktadır. Bu nedenle reklam oldukça önem arz etmektedir. Kültür endüstrisi ve reklam olgusu iç içe geçmiş durumdadır. Gerek ekonomik, gerekse de teknik açıdan bütünleşmiş, birbirine entegre olmuştur. Kültür endüstrisinin unsurları, çok dikkat çekici bir o kadar da kolay, belirli bilgi, beceri ve ustalığa sahip olan sade ürünlerdir (Horkheimer ve Adorno, 1996: 58). Burada amaçlanan temel gaye tüketiciye kolay bir şekilde ulaşabilmek ve onu tahakküm altına almaktır.

Adorno ve Horkheimer kültür endüstrisinin liberal endüstri toplumlarından çıktığını yorumlarken bu durumu son derece olağan karşılamışlardır. Çünkü liberal endüstrinin 
yer aldığı ülkelerdeki radyo, televizyon ve diğer kitle iletişim araçlarının kendine özgü bir yapısı bulunmaktadır. Onlara göre medyanın sermayeli bir yapısı bulunmaktadır. Bu sermayenin temel amacı ise kar elde etme arzusudur. Nitekim günümüz medya yapısı incelendiğinde bu durum aynı şekilde devam ettiği anlaşılmaktadır. Kültürel ürünler metaya dönüşmüş olmakla birlikte bu ürünler endüstrinin birer parçası haline gelmiştir. Bu alanda birçok standartlaşmış ürün ortaya çıkmıştır. Kültür endüstrisi ürünlerinin yelpazesi oldukça geniştir. Bunlar arasında televizyon programları, dizileri, filmler, klasik müzik eserleri, caz müzik eserleri ve kültüre dair ürünler yer almaktadır. Nitekim günümüzde bu kültür ürünleri tamamen uzmanlar, profesyoneller tarafından oluşturulmaktadır. Yani bu kültür ürünlerinin üretimi tamamen fabrikalarda kullanılan bant sistemine göre organize edilmektedir. Yani kısacası kültürel ürünler birer meta konumunda yer almaktadır (Koluaçık, 2017: 152). Dolayısıyla televizyon programlarının da birer meta halini aldığını söyleyebilmek mümkündür. Bu nedenle kültür endüstrisi çerçevesinde televizyon programlarını irdelemek yerinde olacaktır.

\section{Kültür Endüstrisi Çerçevesinde Televizyon Programları}

Adorno'nun kültür endüstrisi konusunda görüşleri dikkate değerdir. Ona göre kültür endüstrisi aldatıcı olmakla birlikte üretilen her türlü içerik pazara yönelik metadan farklı değildir. Kültür endüstrisi sanat eseri değil piyasaya yönelik meta üretmektedir. Geç kapitalizmin gelişim göstermesiyle birlikte artık bütün programlar ürünler pazara yönelik gerçekleştirilmekte ve bu programların, ürünlerin hızlı bir şekilde tüketilmesi amaçlanmaktadır. Kültür endüstrisi, en hızlı ve en çabuk yoldan kazanç elde etmeyi ön plana çıkarmaktadır (Koluaçık, 2017: 141) Yani seri üretim ve seri tüketim söz konusudur. Bu durum gerçek bir sanat eserinin ortaya çıkmasını engellemekte, birbirine benzer türde programlar ve içerikler üretilmektedir.

Televizyon programlarında kültür endüstrisinin etkisi açık bir şekilde görülmektedir. Bütün bunlara ek olarak kültür endüstrisi sisteme yukarıdan entegre olmakta ve buradan kullanıcılara sunulmaktadır. Televizyon programları kitlelerin doğrudan tüketimi için hazırlanmaktadır. Gerek Türkiye'de, gerekse de dünyada bu durumun meydana geldiği açık bir şekilde görülmektedir. Bu tarz programlarda sanat, hiçbir şekilde önemli olmamakla birlikte üretim ve değişim mantığı önem arz etmektedir. Bu düşünceyi birkaç örnekle açıklayabilmek mümkündür. Örnek vermek gerekirse; aksiyon, porno ve western filmlerin birçoğunda sanatsal içerik bulunmamakla birlikte tamamen piyasa ve izlenme gayesiyle üretilmiş standart özellik taşıyan metalar olduğu görülmektedir. Kitle iletişim araçlarının kültür endüstrisine etkisi de farklııık arz etmektedir. Televizyonun etkisi, radyoya oranla oldukça büyüktür. Ancak programlarda karmaşık bir yanılsama da söz konusudur. İzleyiciler (ki bunlar kültür endüstrisi açısından değerlendirildiğinde tüketici olarak değerlendirilmektedir) programlarla karşı karşıya kaldıklarında yanılsama durumunu açık bir şekilde görmektedirler (Alemdar ve Erdoğan, 1994: 202).

Hem görsel hem işitsel bir kitle iletişim aracı olan televizyon üzerine kuramcılar farklı akıl yürütmeler gerçekleştirmiş ve fikirlerini beyan etmişlerdir. Bu isimler arasında 
David Thorburn (Mutlu, 1991) da yer almaktadır. Ona göre televizyon ekranı aracılığıyla izleyicilere sunulan kültürel "artifact”ler hem yapay yani kurmaca hem de popüler kültür metinlerini yansıtmaktadır. Televizyon programları üretildikleri toplumun kültür tarihi üzerine düşünülmesine de olanak tanımaktadır. Ayrıca televizyon içinde yaşanan toplumun hikâye anlatıcısı konumundadır. Televizyon programları kültür endüstrisi açısından değerlendirildiğinde, bu ürünlerin toplumun bütün kesimine hitap ettiği görülmektedir. Böylece sınıf, gelir, cinsiyet, eğitim gibi kıstaslar aşılmakta ve böylece standart artifactler oluşmaktadır.

Televizyon programları kanaat, davranış ve tutumları da biçimlendirebilme gücüne sahiptir. Dolayısıyla televizyonun fikir ve düşüncelere doğrudan etki ettiği düşüncesini ortaya koyan bir diğer önemi kuramcı George Gerbner'dir. Gerbner (akt. Erdoğan, 1998: 149-159) kendisi tarafından ortaya konan "ekme kuramı"nda televizyonun etkilerinin kısa vadeli ve belli olaylardan çıkmadığını aktarmıştır. Gerbner, bireylerin tutum ve davranışlarının şekillenmesinden en etkili kitle iletişim aracının televizyon olduğunu dile getirmiştir. Ona göre televizyon artık gündelik kültürel hayatın başat bir yapı taşı haline gelmiştir. Gerbner, televizyon dinden çok daha güçlü bir kültürel bağ sağladığını belirtmiştir. Televizyonun izleyicilerin fikir, görüş ve düşünce kalıplarını yıktığını beyan eden Gerbner, geleneksel farklıııkların televizyon aracılığıyla yok olduğunu belirtmiştir.

Pierre Bourdieu'nun televizyon konusundaki tespitleri de oldukça önem arz etmektedir. Çünkü Bourdieu bir yandan televizyonun toplumsal gelişmeye katkısı olduğunu dile getirmiş, diğer yandan ise bu kitle iletişim aracını eleştirel bir perspektiften ele almıştır. Ona göre televizyon; her yaştan her kesimden izleyiciye ulaşmaya imkân veren teknolojik bir araçtır. Fakat televizyon programlarında sansür uygulandığını ve neticesinde özerklik yitiminin meydana geldiğini ifade etmiştir. Bourdieu'ya göre televizyonda siyasi müdahale ve siyasi denetim açık bir şekilde kendisini göstermektedir. Hatta bu müdahaleler sıkça yaşanmaktadır. Aynı şekilde ekonomik sansür olgusunu da dile getiren Bourdieu (1992: 22-28), televizyon sahiplerinin ekonomik şirketler elinde bulunduğunu belirterek, reklam verenlerin yayın içeriklerine doğrudan müdahale edeceğinin altını çizmiştir. Nitekim bu durum kültür endüstrisine de destek vermektedir. Çünkü kültür endüstrinin reklamlarla da doğrudan ilişkisi bulunmaktadır. Seri üretim ve seri tüketim reklamcılığı da desteklemektedir. Reklamlar program içeriklerine de müdahale edebilme imkânı sağlamaktadır.

Kuramcıların da ifade ettiği gibi televizyon ve kültür arasında sıkı bir bağ bulunmaktadır. Televizyon, gerek Türkiye'de, gerekse de dünyada son yıllarda insanların en çok vakit ayırdığı kitle iletişim araçlarından biri olarak nitelendirilebilmektedir. İnsanların gündelik hayattaki yorgunluklarını, sıkıntılarını televizyon aracılığıyla atabilmektedirler. Aynı zamanda televizyon boş zaman değerlendirme aracı olarak da nitelendirilebilmektedir. Yarışmalar, diziler, magazin ve haber programları doğrudan tüketime sevk edici unsurları bünyelerinde barındırmaktadır. Bu durum kimi zaman bilinçli kimi zaman da bilinçsiz bir şekilde gerçekleşebilmektedir. Televizyon aracılığıyla sunulan kişi ve hayatlar izleyicilerin de dikkatini çekmekte, hatta izleyiciler burada sunulan kişilere, 
hayatlara özenmektedirler. Onlar gibi giyinmek, onların kullandıklarını kullanmak son dönemlerde sıkça karşılaşılan olgulardandır. Bu durum kısaca sembolik tüketim olarak nitelendirilebilmektedir. Sembolik tüketimle karşı tarafa sosyal statü ve sınıfa ilişkin mesajlar verilmektedir (Baran ve Baran, 2014: 171) Dolayısıyla bu durum televizyon programlarında kültür endüstrisini şekillendirmektedir. Günümüzde yarışma programları da reyting olgusunun önlenemez yükselişiyle birlikte kültür endüstrisinin bir parçası haline gelmekte, özellikle yurt dışından ithal edilen yabancı formatlı yarışma programlarında bu durum etkisini açık bir şekilde hissettirmektedir.

\section{5. 'Yetenek Sizsiniz Türkiye' Programına Yönelik Eleștirel Bir Analiz}

Amerika Bileşik Devletleri'nde "America Got Talent" ismiyle seyircilerle buluşan ve Türkiye'de de 2009 yılından itibaren Show TV'de yayınlanmaya başlayan "Yetenek Sizsiniz" isimli yarışma programı 2012'te kanal değiştirmiş ve Star TV'ye transfer olmuştur. 2014 yılından itibaren ise TV8'de yayın hayatına devam etmektedir. Programın yapımcısı da Acun Ilıcalı'dır. FremantleMedia'nın projelendirdiği bu format Türkiye'de oldukça popüler bir hale gelmiştir (Acun Medya, 2018). Programın çekimleri Türkiye genelinde yer alan üniversitelerde gerçekleştirilmektedir. Sadece yurt içinden değil, yurt dışından gelen yarışmacılar da yeteneklerini sergilemekte ve jüri tarafından beğenilmeye çalışılmaktadır. Programın jüri üyeleri arasında Acun Ilıcalı, Hülya Avşar, Ali Taran, Sergen Yalçın, Eser Yenenler, Özgü Namal, Murat Boz, Seda Bakan, Demet Evgar ve Oylum Talu gibi isimler yer almıştır. Yarışma Türkiye genelinde oldukça yoğun izlenme oranına sahiptir. Yarışmaya yönelik medya kuruluşlarında da haberler çıkmaktadır.

\subsection{Araștırmanın Yöntemi}

$\mathrm{Bu}$ çalışmada nitel araştırma yöntemlerinden içerik analizi tekniği kullanılmıştır. Nitel araştırmaya yönelik farklı tanım ve görüşler mevcuttur. Çünkü nitel araştırma başıı̆ı altında birçok alt yöntem bulunmaktadır. "Durumsal araştırma", "etnografi", "yorumlayıcı araştırma", "antropoloji”, "içerik analizi”, "tanımlayıcı araştırma”, "teori geliştirme", "doğal araştırma" bu başııklardan yalnızca birkaçıdır. Bu araştırmaların alt yapısı birbirine benzediğinden ötürü hepsi "nitel" kategorisi altında toplanmaktadır (Yıldırım, 1999: 9). İçerik analizi; "metodolojik araç ve teknikler bütünü, kontrollü yorum yapma, nesnel, sistematik ve nicel yollardan betimleme, önceden belirlenmiş ölçütlere göre inceleme, anlam çıkarma, açık talimatlara göre nicelleştirme işlemi, niteli nicele dönüştüren bir işlem, kavramların ölçülmesi ve belirli bir anlam çıkarılması için kategorilere ayırma" şeklinde ifade edilebilmektedir (Tavşancıl ve Aslan, 2001: 21-22).

\subsection{Evren ve Örneklem}

Çalışmanın evrenini Yetenek Sizsiniz Türkiye programının tüm bölümleri oluşturmaktadır. Araştırmada rastgele olarak da ifade edilen seçkisiz örneklem yöntemi tercih edilmiştir. Evreni aynı oranda temsil edeceği düşünülen programlardan tercih edilen yarışmacılar ve bölümler araştırmaya dâhil edilmiştir. Bu bağlamda 
seçilen 6 yarışmacının performansı ve jüri değerlendirmeleri araştırmanın örneklemini oluşturmaktadır. Ayrıca örneklemin tespiti esnasında program için tercih edilen yarışmacıların bir takım kriterlere sahip olması ve farklılık arz etmeleri amaçlanmıştır. Yarışma katılım formundan bu durum çok daha iyi anlaşılabilmektedir. Araştırma özellikle medyada diğerlerine oranla daha farklı niteliklere sahip oldukları için sıklıkla yer bulan yarışmacılarla sınırlı tutulmuştur.

\subsection{Bulgular ve Yorum}

Temel olarak "Yetenek Sizsiniz Türkiye isimli program popüler kültür ve kültür endüstrisine hizmet etmekte midir?" sorusuna cevap arayan bu çalışmada ilk olarak 29.09.2012 tarihli program incelenmiştir. Program çok nadiren görülen bir olaya sahne olmuştur. Yarışmaya katılan Âdem Oğuz, jüri üyeleri ve tüm izleyenleri şok eden bir olaya imza atarak Hülya Avşar'a evlenme teklifinde bulunmuştur. Yarışmacı Oğuz öncelikle illüzyon gösterisini sergilemiş ve bu olay üzerin jüri üyelerinden tam not almayı başarmıştır. Bilindiği üzere popüler kültür "hızlı üretim ve hızlı tüketim kültürü" olarak da ifade edilebilmektedir. Popüler kültür ürünleri ve olaylarının etkisi hızlı bir şekilde geçmektedir. Nitekim Fiske (1999: 143-145) popüler kültürün gündelik hayat ve kültür endüstrisinin arasında yer aldığını belirtmiş, halk tarafından oluşturulduğunu beyan etmiştir. Yarışmacı Âdem Oğuz'un Hülya Avşar'a yaptığı evlenme teklifi tam da bu noktada yer almıştır. Teklifin yapıldığı ertesi gün birçok haber sitesinde bu içerik videolu haber formatında yayınlanmış, ancak kısa bir süre sonra etkisini kaybetmiştir. Bu olay popüler kültürün hızlı üretim ve hızlı tüketim durumuna somut bir örnektir. Nitekim; kültür endüstrisi, genellikle yaratıcılık ve özgünlükten uzak olarak, basit kalitesiz birbirinin aynı kolay tüketilebilen seri üretim ürünler ortaya çıkarmaktadır. Program içeriklerinin de aynı şekilde hazırlandığı düşünülürse bu tarz olayların kültür endüstrisi bağlamında değerlendirilebilmesi mümkündür.

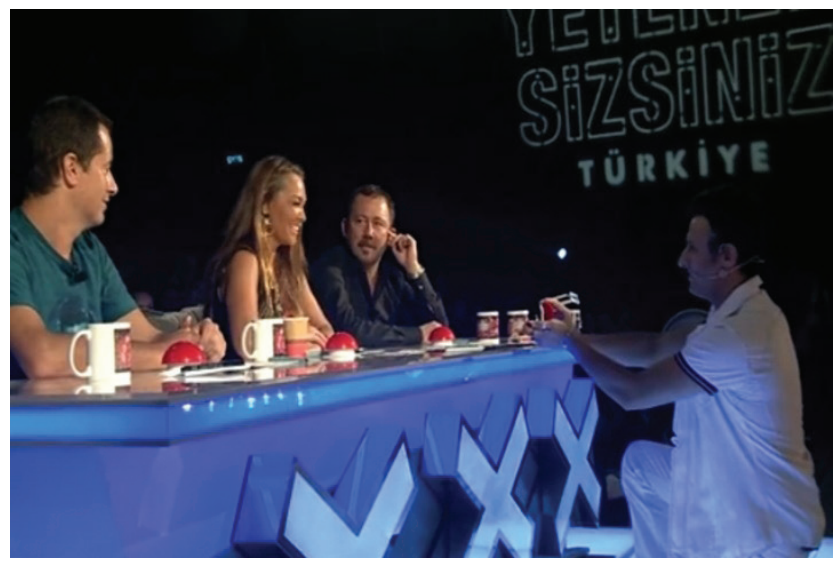

Fotoğraf 1: Yarışmacı Âdem Oğuz'un Hülya Avşar’a evlenme teklifi 
geçerek jüri karşısına çıkan yarışmacı sayısı da bir hayli fazladır. Ancak çocukların da yarışmaya katılması oldukça farklı bir duruma sebebiyet vermektedir. 14.10.2013 tarihli programa Adana'dan katılan 11 yaşındaki Şahin Kendirci jüri üyelerini ve izleyicileri etkilemeyi başarmıştır. "Zoruna mı gitti gardaş" isimli arabesk parçayı seslendiren Kendirci jüri üyelerinin üçünden de evet almıştır. Şarkısını seslendirdikten sonra Kendirci ile sohbet etmeye başlayan Acun Ilıcalı, küçük çocuğa babasının mesleğini sormuştur. Kendirci, babasının hamallık yaptığını ifade etmiştir. Adorno ve Horkheimer (1996) bireylerin edilgen yapısının kültür endüstrisi aracılığıyla (ki bunlar film, müzik, televizyon programları, diziler, magazinel içerikler olduğunu ifade etmektedirler) sağlamlaştırıldığını ifade etmektedir. Kültür endüstrisi bireylerin yaşam tarzını değiştirmekte ve dönüştürmektedir. Arabesk acılara hitap etmekte ve duygu yoğunluğu meydana getirmektedir. Nitekim yarışmacı Kendirci hem acıklı bir parça seslendirmiş, ardından kendi yaşamının da maddi anlamda sıkıntılı geçtiğini belirtmiştir. Yapımcılar program sonrası küçük yarışmacıya albüm teklifinde bulunmuşlar ve bu durumu maddi kazanca çevirmeye çalışmışlardır. Kızıldağ'a (2001: 78) göre; popüler kültürün yoğun baskısı altındaki gençlerin popüler idolleri bulunmaktadır. Bu noktada Şahin Kendirci'nin arabesk türde şarkıları seslendirmesi, Türkiye'de bu alanda eserler seslendiren isimlerin baskın yapısını ortaya koymaktadır. Bu isimler arasına İbrahim Tatlıses, Ferdi Tayfur, Orhan Gencebay, Müslüm Gürses’i sayabilmek mümkündür.

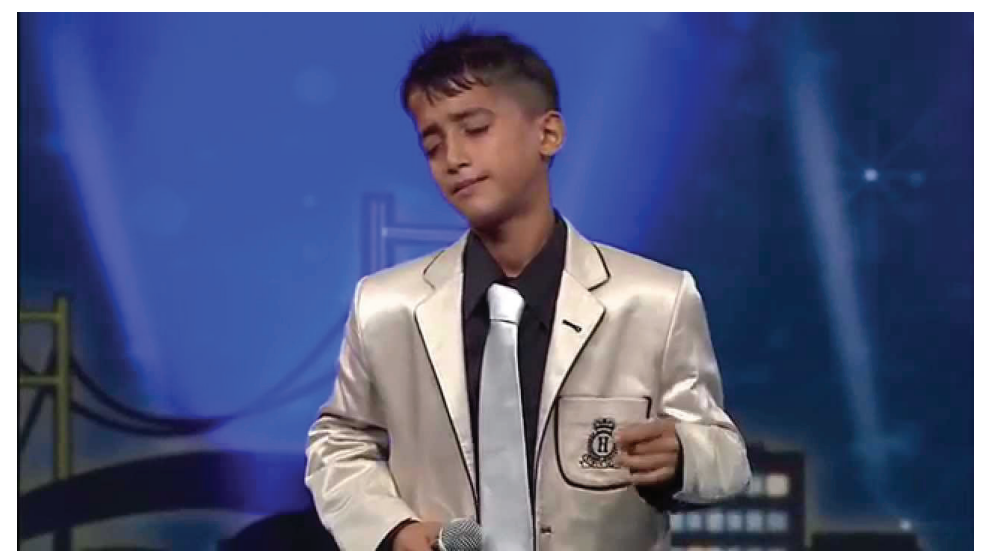

Fotoğraf 2: Yarışmacı Şahin Kendirci'nin performansı

26.10.2013 tarihli program da yine farklı bir olaya sahne olmuştur. Kızgızistan'dan gelen 15 yaşındaki Azamad Abdumirza isimli yarışmacı şovunu gerçekleştirmiş ve jürinin değerlendirmesini alabilmek için sahnede beklemeye geçmiştir. Rusça'dan Türkçe'ye tercüme etmek üzere sahneye çıkan Rafet isimli diğer bir yarışmacı Azamad Abdumirza'nın söylediklerini tercüme etme konusunda oldukça başarısız olmuştur. Bu olay üzerine jüri üyeleri ve izleyiciler kahkahalara boğulmuşlardır. Tercüme sonrasında Acun Ilıcalı'nın gülmekten gözünden yaş geldiği görülmüştür. Aristoteles tiyatro ve müzik gibi kültürel ürünlerin haz verdiğini ifade etmiştir. Sıradan insanlarda haz alma yetilerinin oluşmadığını ifade eden Aristoteles (Oskay, 2001: 12-14) sanatın her grup için 
farklılaştığını savunmaktadır. Ancak buradaki eğlence unsuru sanatsal bir gerekçeye bağlı değildir. Çevirmenin kişisel yetisinden kaynaklı bir durum mizahi bir açıdan ele alınmıştır. Nitekim bu durum da popüler kültür çerçevesinde değerlendirilebilmektedir.

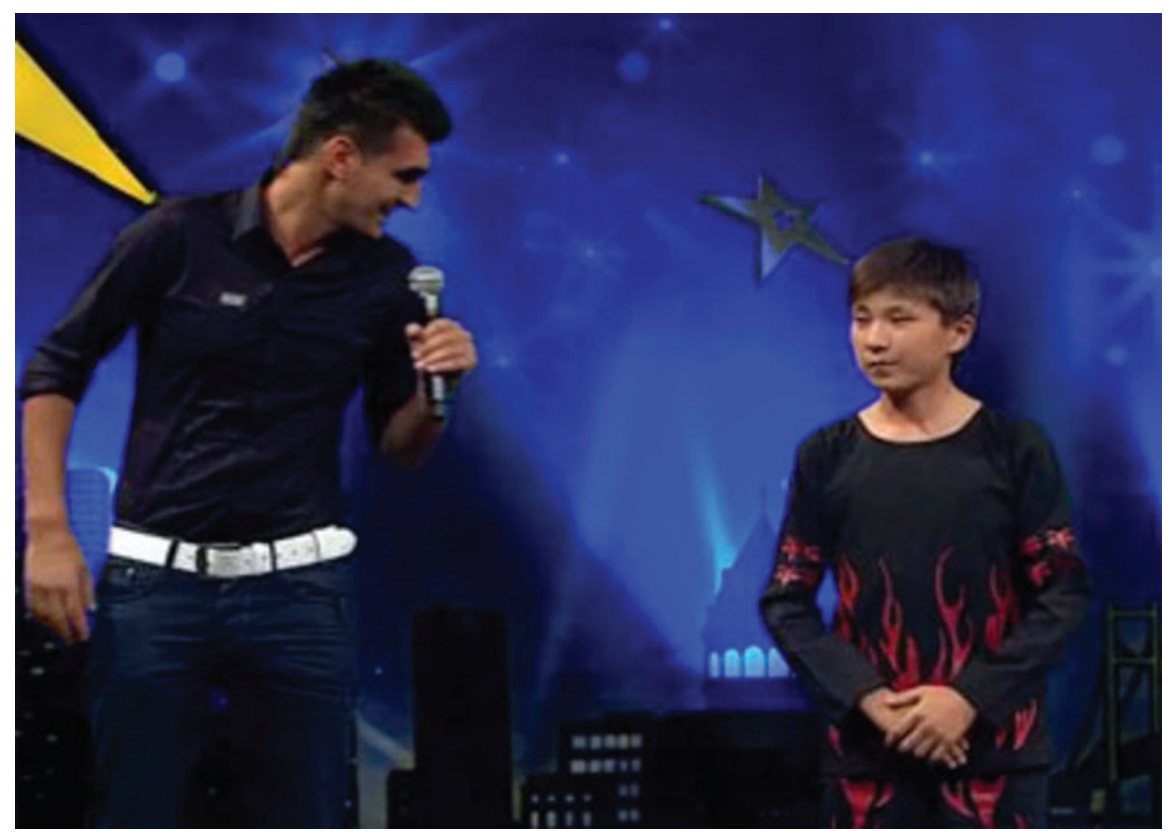

Fotoğraf 3: Azamad Abdumirza ve çevirmen Kadir'in sahnedeki anları

Çaldıkları farklı enstrümanlarla 27.09.2014 tarihli Yetenek Sizsiniz Türkiye programına katılan Balkan Beats Orkestrası kendilerine özgü tarzı nedeniyle hem jüri üyelerinin hem de seyircilerin ilgisini çekmiştir. Sanatsal yeteneklerini sergiledikten sonra kenara geçen ekibin en yaşlı üyesi oryantal dans yaparak izleyicileri şaşırtmıştır. Orkestrayı öven jüri üyesi Murat Boz, "Amca seninle dans edebilir miyim? Senin gibi titretmek istiyorum." diyerek sahneye çıkmış ve orkestranın en yaşlı üyesiyle karşılıklı olarak oryantal dansı yapmıştır. Jüri üyelerinin tümünden evet alan orkestra bir üst tura geçmeye hak kazanmıştır. Tüketim kültürünü sadece belirli bir gereksinimin yönelik bir faaliyet olarak nitelendirmek pek de doğru olmamaktadır (Bocock, 2005). Çünkü kültür endüstrisinin etkisiyle tüketim artık bireylerin belirli bir kimliği inşa etme, kendilerini ifade edebilme ve bireyselleşirken toplumsallaşan bir yapıya ulaşmıştır. Yarışmacıların da kendilerini ön plana çıkarma arayışları farklı bir kimlik oluşturma ve üne kavuşma amacı taşımaktadır. Çünkü ün, beraberinde maddiyatı da getirmektedir. Ancak popüler kültürün etkisiyle birlikte televizyonda yer alan kişilerin kimlikleri birbirine benzer bir boyuta ulaşmaktadır. Bu bağlamda popüler kültürün tamamen pazar için üretilen, sipariş edilen, ısmarlama ürünler sunduğunu söyleyebilmek mümkündür (Erdoğan, 2004: 4). Popüler kültüre bağlamında değerlendirilen Yetenek Sizsiniz Türkiye isimli yarışma programında birbirine benzer türde içerikler ve kişilerin programda tercih edildiği görülmektedir. 


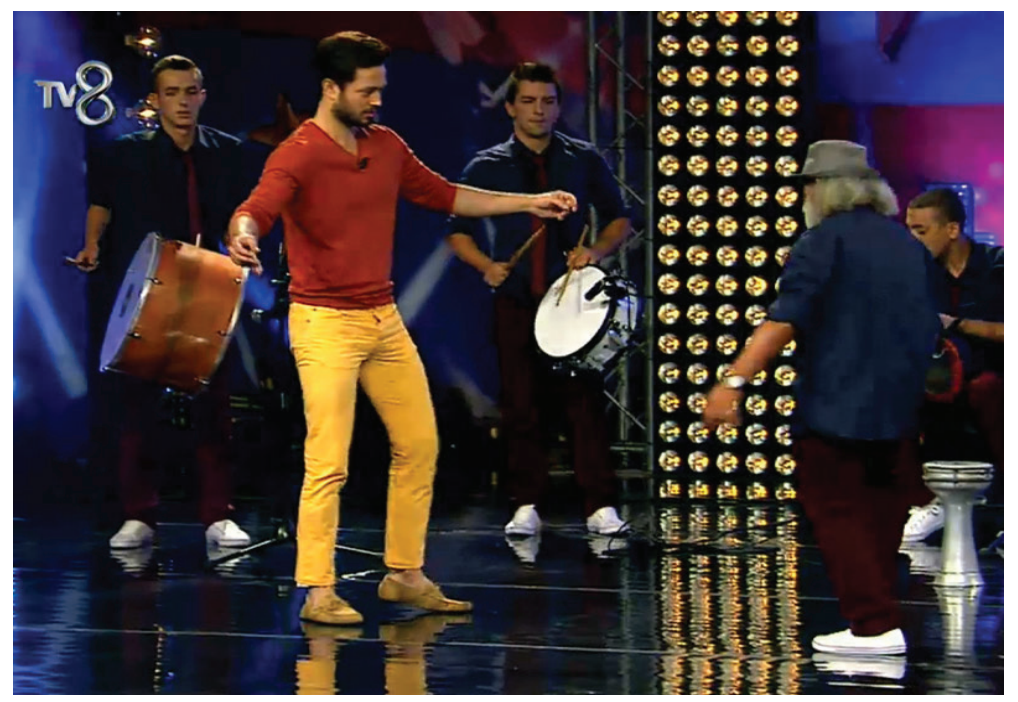

Fotoğraf 4: Jüri üyesi Murat Boz’un oryantal dans gösterisi

Yetenek Sizsiniz Türkiye isimli programa hemen hemen her kesimden, her özellikten yarışmacıların da ilgi gösterdiği ve katıldığı görülmektedir. Bunlardan biri de 23.11.2014 tarihinde yarışmaya katılan Sakarya doğumlu Riccardo Mancini'dir.

Mancini; Dean Martin, Julio Iglesias, Louis Armstrong ve Tom Jones gibi dünyaca ünlü isimlerin şarkılarını seslendirmiş ve jüri üyelerinin büyük beğenisini kazanmıştır. Jüri üyelerinden Özgü Namal, Mancini'nin performansından oldukça etkilenmiş ve “ Ben şarkılara değil size ağladım. Ne acayip bir şey bu yetenek değil mi yaşı yok. Işste çıkmak istediği zaman nasıl çıkıyor. Bu çok büyük bir cesaret” ifadelerini sarf etmiştir. Özgü Namal en sonunda gözyaşlarını tutamayarak ağlamıştır.

Postmodern toplum irdelendiğinde bunun gösteri toplumu olduğu görülmektedir. Nitekim Yetenek Sizsiniz Türkiye de gösteri toplumunun bir parçası durumdadır. Gösteri toplumunda tüketici (Debord, 1996) gerek gösterinin bir parçası olmak için çabalamakta, gerekse de kendini tanımlamak için birtakım yolları keşfetmeye çalışmaktadır.

Yetenek Sizsiniz Türkiye'de birbirinden farklı yarışmacılar bir arada yer almakta ve farklı yaşam tarzlarına sahip olduklarından dolayı özgün yapıyı bünyelerinde barındırmaktadırlar. Bu durum izleyicinin de dikkatini çekmektedir. İzleyici her zaman farklı ve özgün olanı sevmekte ve ilgi göstermektedir. Öte yandan hırs ve umut bileşkesinde ortaya çıkan bu tarz yarışma programları mutluluk, umut ve hayal kırıklıklarını da bünyesinde barındırmaktadır (Çaplı, 2002:191). Bu durum kapitalist toplumların egemenler değerlerini pekiştirmekte, böylece izleyiciler var olan durumla özdeşleşerek imgesel dünya içerisinde umutvari bir şekilde yaşayabilmektedirler. 


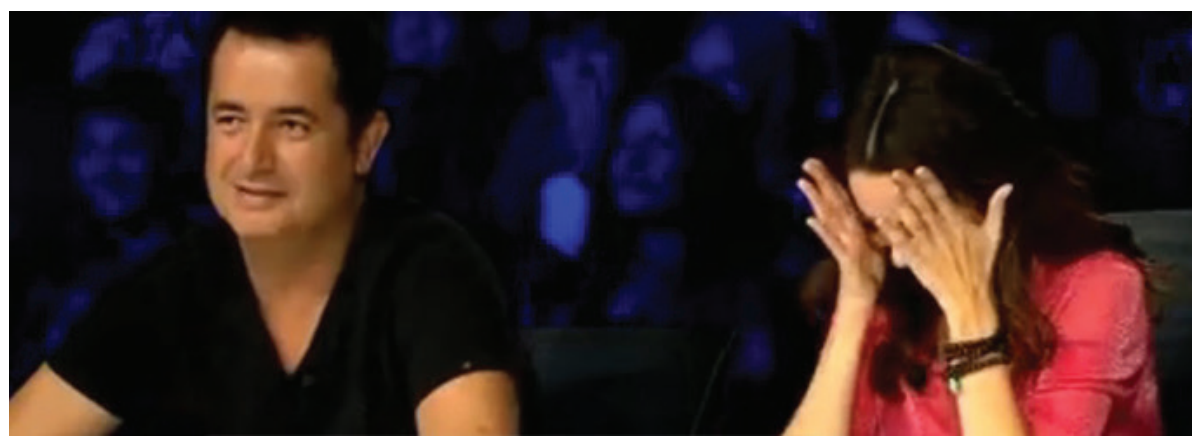

Fotoğraf 5: Riccardo Mancini'nin performansı sonrası Özgü Namal’ın duygusal anları...

Müziğe olan ilgisi ve yeteneğiyle ön plana çıkan bir diğer isim ise opera söyleyen 12 yaşındaki Mehir Miray Atıcı olmuştur. 14.10.2017 tarihli programda yeteneğini sergileyen Atıcı, jüri üyelerini derinden etkilemeyi başarmıştır. Bursa İnegöl'den programa katılan 12 yaşındaki Mehir Miray Atıcı, jüri üyeleri Acun llıcalı, Hülya Avşar ve Ali Taran'ın ilgisini çekmiş ve jüri üyelerinden üç evet almıştır. Seyirciler ise bir arenada yer alıyor gibi yarışmacıları seyretmektedir. Seyirci olgusu Eski Roma'ya kadar gitmektedir (Aydoğan, 2004: 11). Bundan dolayı gerek stüdyoda, gerekse de televizyon başında yer alan seyircilerin izleme eylemini gerçekleştirmektedir. Arena mantığı Yetenek Sizsiniz Türkiye yarışmasında da kendisini göstermektedir. Yarışmacı tıpkı bir gladyatör gibi arenada savaşmakta ve ayakta kalmaya çalışmaktadır. Atıcı, yaşça diğerler yarışmacılara oranla daha küçük olmakla birlikte opera konusunda yeteneğini sergilemesi onu farklı kılmaktadır. Opera popüler müzik faaliyeti içerisinde yer almamaktadır. Ancak yarışmanın popüler kültürü teşvik etmesi ve sunulan içeriklerin metalaşması kültür endüstrisi olgusunu ön plana çıkarmaktadır. Modern kültürün üretim pratikleri değerlendirildiğinde maddiyatın had safhada olduğu görülmektedir. Teknolojilerin ve metaların maddi dünyası da kültürdür (Hall 1995:118). Dolayısıyla sanatsal bir ürünün dahi metalaşması yarışmanın kapsamı içerisinde olağan karşılanmaktadır.

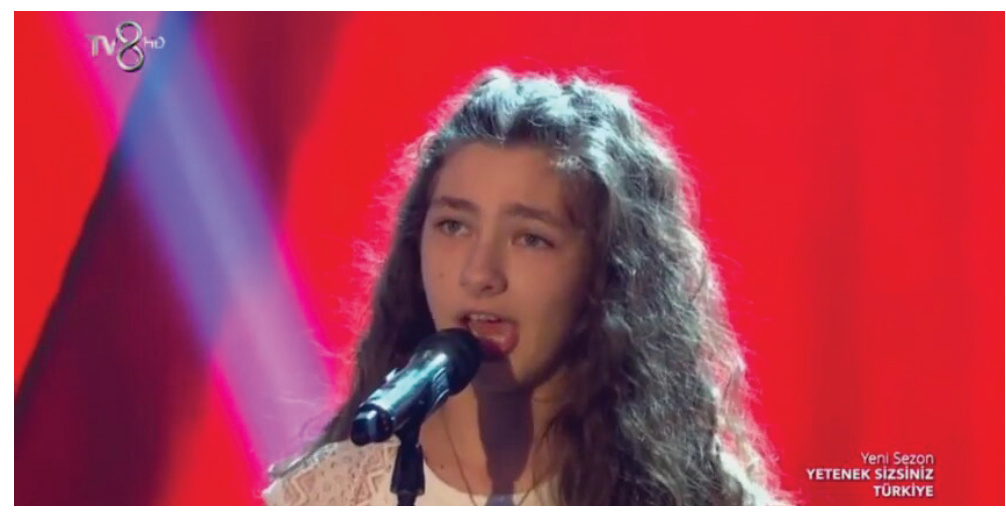

Fotoğraf 6: Mehir Miray Atııı'nın Yetenek Sizsiniz Türkiye'de performans sergileme anı 
Görüldüğü üzere, Yetenek Sizsiniz Türkiye yarışma programı alışılagelmişin dışında birçok unsuru bünyesinde barındırmaktadır. Gerek jüri üyeleri, gerekse de yarışmacılar bu noktada farklılık arz etmektedir. Nitekim popüler kültür ve kültür endüstrisi bu tarz unsurları kullanarak insanları etkilemeyi hedeflemekte, böylelikle başat bir form oluşturmayı amaçlamaktadır. İncelenen programlarda bu durum açık bir şekilde kendisini göstermiştir.

\section{Sonuç}

Gelişen iletişim teknolojileri her geçen sosyolojik değişimler yaratmakta ve kültürel yapıda önemli dönüşümler meydana getirmektedir. Kültürel yapı, ekonomik, siyasal, sosyal alanı da etkilemiş yozlaşma, yabancılaşma, yalnızlaşma gibi kavramların ön plana çıkmasına neden olmuştur. Televizyonun etkin bir kitle iletişim aracı olarak ortaya çıkması insan hayatını derinden etkilemiştir. Ekran başında geçirilen sürenin artması farklı program türlerinin ve formatlarının oluşumuna sebebiyet vermiştir. Program içeriklerinin farklılaşması ve televizyon programlarında ön plana çıkan reyting olgusu izleyicilerin daha hızlı tüketebileceği popüler kültür ürünlerinin ortaya çıkmasına neden olmuş ve kültür endüstriyel bir boyuta ulaşmıştır.

Frankfurt Okulu'nun kurucuları arasında yer alan Adorno ve Horkheimer modern hayatın birey ve kültür üzerinde olan etkisini uzun yıllar araştırmış ve bu durumu kültür endüstrisi ile açıklamışlardır. Kitle kültürünü popüler kültürün bir adım ötesi şeklinde değerlendirebilmek mümkündür. Zira kültür endüstrisi mevcut olan kültürün oluşumunda kitlelerin rolünün azaldığını ve bütünün parçalarının kendine uymak mecburiyetinde bıraktığı bir düzeni işaret etmektedir. Amerika Bileşik Devletleri'nde gelişim gösteren eğlenceye dayalı yayıncılık sanatı meta, kültürü tek tipleştirilmiştir. Kültür endüstrisinin gayesi insanlar üzerinde bir hegemonya kurmak ve özeli genele indirgemektir.

Kültür endüstrisi sadece Türkiye'de değil, tüm dünyada da yoğun bir nüfuza sahiptir. Kültür endüstrisi gerek teknoloji, gerekse de radyo, televizyon gibi iletişim araçlarıyla toplumun her alanına müdahil olmayı amaçlamakta; kapitalizm döngüsü kültür ve sanatı yozlaştırarak bireyin öznelliğini yitirmesini hedeflemektedir. Günümüzde ithal formatlı yarışma programlarında da bu tarz bir durum söz konusudur. Çünkü bu programlarla amaçlanan reyting olgusunun ön plana çıkması; reklam ve pazarlama faaliyetlerinin had safhaya ulaşmasıdır. Reklam daha çok ticari kar elde edilmesini sağlamakta ve bu durum program içeriklerinde tamamen reyting merkezli bir yapının ortaya çıkmasına neden olmaktadır.

Yarışma programları ise günümüzde izleyiciler tarafından yoğun ilgi görmektedir. Yarışmacıların hedefe ulaşmak için gerçekleştirdikleri her türlü çaba ve mücadele, beraberinde hırs ve rekabeti getirmektedir. Hırs ve rekabet olgusu bencillik duygusunu da tetiklemekte, bireylerin içinde bulundukları durumdan daha farklı bir şekilde hareket etmelerine neden olmaktadır. Türkiye'de ve dünyada yarışma programlarına atfedilen değer oldukça büyüktür. Yarışmacılarla özdeşleşme, zirveye ulaşma arzusu ve 
neticesinde elde edilecek ödül, yarışma programlarını diğer türlerden ayırmaktadır. Yarışma programlarına dair haberler, içerikler medyada da yankı bulmakta, sosyal paylaşım ağlarında kullanıcılar yarışmacıları kritize etmektedirler.

Proje tasarımcısı FremantleMedia olan ve Türkiye'deki yayın haklarını Acun Ilıcalı'nın elinde bulundurduğu "Yetenek Sizsiniz Türkiye" isimli yarışma programı yayınlandığı çoğu gün toplam izlenme oranlarında en üst sıralarda yer almaktadır. Buradan da anlaşılacağı üzere Türkiye'de bu yarışma programına yoğun ilgi gösterilmektedir. Programın, formatı içeriği oldukça özgün bir yapıya sahiptir. Gerek yarışmacıların, gerekse de jüri üyelerin farklı ve alışılagelmişin dışında karakterlere sahip oldukları görülmektedir. Gerek yeteneği, gerekse de hayat hikâyesi farklı olan isimler öncelikle ön değerlendirmeye tabii tutulmakta, ön değerlendirmeyi geçen yarışmacılar program esnasında yeteneklerini sergilemektedirler. Yarışmacıların yanında medyatik isimlerin jüri üyesi olarak seçilmesi de reyting unsurunun ön planda yer aldığının göstergesidir. Ali Taran, Hülya Avşar, Murat Boz, Sergen Yalçın gibi jüri üyeleri magazinel açıdan ön planda yer alan popüler isimlerdir. Bu noktada medyanın oluşturduğu kimlikleri dayattığı da bir gerçektir.

Sosyal medya ve internet teknolojisine rağmen televizyon hali hazırda geniş kitleler tarafından izlenmekte, hatta sunulan içerikler sanal ortamda da ses getirmektedir. Nitekim Yetenek Sizsiniz Türkiye isimli yarışma programı kimi zaman içerikleriyle, kimi zaman katılımcılarıyla sosyal medyada dünya gündeminde kendine yer bulabilmektedir. İncelenen bölümler değerlendirildiğinde gerek yarışmanın kendisinin, gerek jüri üyelerinin, gerekse de yarışmacıların popüler kültüre hizmet ettiği görülmektedir. Yetenek Sizsiniz Türkiye yarışma programında sadece yapılan değerlendirmeler ve jürinin getirdiği eleştiriler önem arz etmektedir. Kimi zaman jüri üyeleri seyirciyi de sürece dâhil etmekte ve onların da yorum yapabilmelerini sağlamaktadırlar. Getirilen ağır eleştiriler, hatta bazı yarışmacıların zaaflarıyla dalga geçilmesi ve bu yarışmacıların zaaflarından dolayı küçümsenmesi karşılaşılan bir durumdur. Bu durum televizyon programlarının toplum üzerinde sahip oluğu değerle doğru orantılıdır.

Yarışmacıların hayat hikâyelerini anlatmaları ve çoğu zaman karşılıklı diyalog şeklinde geçen konuşmalar da "infotainment"in bir parçasıdır. Bu şekilde amaçlanan bilgi ve eğlenceyle birlikte popüler kültürün yükselen bir ivme kazanmasıdır. Aynı şekilde reyting ve reklam olgusu da kültür endüstrisine hizmet edecek içeriklerin hazırlanmasına adeta zemin hazırlamıştır. Kapitalist öğretinin amaçladığı kar elde etme arzusu program aracılığıyla kendini göstermektedir. Birbirinden farklı karaktere, özelliklere sahip olan bireyler tek bir çatı altında toplanmış ve kapitalist dünya düzeninin temellendirilmesi adına bir araya getirilerek yarışmaya dâhil edilmişlerdir. Bu durumun mutlak suretle sorgulanması gerekmektedir. Bireyin yeteneği tamamen metalaştırılmakta ve bunun üzerinden gelir elde edilmesi amaçlanmaktadır. Nitekim yarışmacılar da büyük ödüle ulaşabilme adına yeteneklerini bir meta olarak sunmaktadırlar. Bu çalışma yalnızca Türkiye ile sınırlı olmasına rağmen, program formatında yer alan birçok unsurun dünya ile de benzer özellikler taşıdığı görülmektedir. 


\section{Kaynakça}

Acun Medya (2018). Yetenek Sizsiniz Türkiye, Erişim Adresi: https://yetenek-sizsiniz.acunn.com/, Erişim Tarihi: 16.07.2018.

Adorno, T. W. (2009). Kültür Endüstrisi: Kültür Yönetimi (çev. Nihat Ünler, Mustafa Tüzel, Elçin Gen), İstanbul: İletişim Yayınları.

Aksaçıı̆lu, A. G. ve Yılmaz, B. (2007). Öğrencilerin Televizyon İzlemeleri ve Bilgisayar Kullanmalarının Okuma Alışkanlıkları Üzerine Etkisi, Türk Kütüphaneciliği. 21(1): 3-28.

Alemdar, K. ve Erdoğan, İ. (1994). Popüler Kültür ve Illetişim, Ankara: Ümit Yayıncılık.

Aydoğan, F. (2004). Düşlerimizi Artık Televizyon Koruyor, Medya ve Popüler Kültür Üzerine Yazılar, İstanbul: Kapital Medya.

Baran, T. ve Baran, S. (2014). Televizyon Programları, Sembolik Tüketim ve Toplumsal Yansımaları, Karamanoğlu Mehmetbey Üniversitesi Sosyal ve Ekonomik Araştırmalar Dergisi. (3): 171-175.

Bocock, R. (2005). Tüketim (çev. İrem Kutluk), Ankara: Dost Yayınları.

Bosshart, L. and Macconi, I. (1998). "Defining "Entertainment”, Communication Research Trends. 18 (3): 3-6.

Bourdieu, P. (1999). On Television, New York: The New Press.

Curran, J. P. (1997). “Medya ve Demokrasi”, Medya, Kültür, Siyaset (ed. Süleyman İrvan), Ankara: Ark Yayınları.

Çaplı, B. (2002). Medya ve Etik, Ankara: İmge Kitabevi.

Çiğdem, A. P. (2005). "Popüler Kültür ve Popüler Tiyatro”, Atatürk Üniversitesi Güzel Sanatlar Fakültesi Sanat Dergisi. (8): 47-62.

Çoşgun, M. (2012). "Popüler Kültür ve Tüketim Toplumu", Batman University Journal of Life Sciences. 1(1): 837-850.

Debord, G. (1996). Gösteri Toplumu (çev. Ayşen Ekmekçi, Okşan Taşkent), İstanbul, Ayrıntı Yayınları.

Erdoğan, İ. (1998). “Gerbner'in Ekme Tezi ve Anlattığı Öyküler Üzerine Bir Değerlendirme”, Kültür ve Illetişim. 1(2): 149-180.

Erdoğan, İ. (2004). Popüler Kültürün Ne Olduğu Üzerine, Bilim ve Aklın Aydınlığında Eğitim Dergisi. 5 (57): 1-18.

Erdoğan, İ., Keloğlu İşler, E., Durmuş, N. (2005). Kitle Illetişiminde Pozitivist Ampirik Geleneğin Kuruluşu: Lazarsfeld ve Yönetimsel Araştırmalar. Gazi Üniversitesi İletişim Dergisi. 20 (2): 1-48.

Esslin, M. (1996). Dram Sanatının Alanı (çev. Özdemir Nutku), İstanbul, Yapı Kredi Yayınları.

Fiske, J. (1999). Popüler Kültürü Anlamak, Ankara: Ark Yayınları.

Fiske, J. (2010). Understanding Popular Culture, London, New York: Routledge. 
Güngör, N. (1993). Popüler Kültür ve İktidar, Ankara: Vadi Yayınları.

Hall, S. (1995). "Yeni Zamanların Anlamı”, Yeni Zamanlar (drl. Stuart Hall ve Martin Jacques, çev. Abdullah Yılmaz), İstanbul: Ayrıntı Yayınları, ss.105-124.

Horkheimer, M., Adorno, T. W. (1996). Aydınlanmanın Diyalektiği II (çev. Oğuz Özügül), İstanbul: Kabalcı Yayınevi.

Kızıldağ, Ş. (2001). Pop Müzikten Popüler Kültüre Medya Çocukları, İstanbul: Şehir Yayınları.

Koluaçık, ì. (2017). Eleştirel Teorisyenlerin Kültür Endüstrisi Kavramı Bağlamında Sanata ve Sinemaya Yaklaşımları, Abant Kültürel Araştırmalar Dergisi. 2(3): 135-156.

Mutlu, E. (1991). Televizyonu Anlamak, Ankara, Gündoğan Yayınları.

Mutlu, E. (2005). Globalleşme, Popüler Kültür ve Medya, Ankara: Ütopya Yayınevi.

Oskay, Ü. (2001). Müzik ve Yabancılaşma, İstanbul: Der Yayınları.

Özbek, M. (2002). Popüler Kültür ve Orhan Gencebay Arabeski, İstanbul: İletişim Yayınları.

RTÜK (2018). Televizyon İzleme Eğilimleri Araştırması - 2018, Ankara: RTÜK Yayınları.

Storey, J. (2000). Popüler Kültür Çalışmaları (çev. Koray Karaşahin), İstanbul: Babil Yayınları.

Tavşancıl, E., Aslan, A. E. (2001). İçerik Analizi ve Uygulama Örnekleri, Ankara: Epsilon Yayınları.

Türkoğlu, N., (2003), Kitle İletişimi ve Kültür, İstanbul: Naos Yayınları.

Uyguç, Ü., Genç, A. (1998). Radyo Televizyon Haberciliği, İstanbul: Avcıol Yayınevi.

Yıldırım, A. (1999). Nitel Araştırma Yöntemlerinin Temel Özellikleri ve Eğitim Araştırmalarındaki Yeri ve Önemi, Eğitim ve Bilim. 23 (112): 7-17. 